Onomástica Desde América Latina, n.3, v.2, janeiro - junho, 2021, p. 30 -58. ISSN 2675-2719

https://doi.org/10.48075/odal.v0i0.25970

\title{
Eventos históricos e os impactos antroponímicos: a influência da Era da hortelã na antroponímia de Palotina $-\mathbf{P R}^{1}$
}

\section{Historical events and anthroponomical impacts: the influence of Era da Hortelã on the anthroponomy of Palotina - PR}

\author{
Jessica Paula Vescovi \\ Instituto Federal do Paraná (IFPR) \\ Doutora em Letras - Unioeste \\ https://orcid.org/0000-0002-8635-1068 \\ jessica.vescovi@ifpr.edu.br
}

\section{Resumo}

A antroponímia pode revelar importantes dados sobre a história de um local e ser influenciada por momentos históricos. No munícipio de Palotina, região oeste do Paraná, houve, na década de 1970, um movimento migratório, nomeado Era da Hortelã, o qual contribuiu significativamente para a consolidação da antroponímia local. Até então, a região era colonizada por sulistas, imigrantes oriundos da região sul do país, mas, com a produção da menta, houve a imigração de pessoas que eram oriundos de outras regiões do Brasil que não a região sul para o trabalho no cultivo da erva. Levanta-se, então, a seguinte questão: há mudança no sistema antroponímico decorrente deste movimento migratório? Com o referido questionamento e tomando por base os estudos de Vescovi (2015; 2016), intenta-se apresentar informações relativas aos sobrenomes e aos prenomes existentes no local antes e depois deste momento, considerando os estudos de Seide (2013a, 2013b, 2013c) sobre prenomes tradicionais e modismos. A análise feita demonstra que a história de uma comunidade pode ser comprovada por meio dos dados antroponímicos, pois foi possível correlacionar as mudanças antroponímicas, tanto em âmbito etimológico quanto em surgimento de outros prenomes não presentes até então, com as informações sobre a história do município.

Palavras-chave: Onomástica; Antroponomástica Histórica; Era da Hortelã

\begin{abstract}
Anthroponomy can reveal important data about the history of a place and be influenced by historical moments. In the city of Palotina, in the western region of Paraná, there was, in the 1970s, a migratory movement, named Era da Hortelã, which contributed significantly to the consolidation of local anthroponomy. Until then, the region was colonized by southerners, immigrants from the southern region of the country, but with the production of mint, there was an immigration of people who were from other regions of Brazil other than the southern region to work in cultivation of the herb. The question then arises: is there a change in the anthroponomical system resulting from this migratory movement? With this question and based on the studies of Vescovi $(2015 ; 2016)$, it is intended to present information regarding the surnames and first names existing in the place before and after this moment, considering the studies by Seide (2013a, 2013b, 2013c) about traditional first names and fads. The analysis made shows that the history of a community can be verified through anthroponomical data, since it was possible to correlate anthroponomical changes, both in
\end{abstract}

\footnotetext{
${ }^{1} \mathrm{O}$ estudo apresentado neste artigo é referente à dissertação de mestrado defendida por Vescovi (2015) e em artigo científico publicado por Vescovi (2016) no tocante aos aspectos antroponímicos relativos ao período da menta no munícipio de Palotina, Paraná, Brasil.
} 
Onomástica Desde América Latina, n.3, v.2, janeiro - junho, 2021, p. 30 -58. ISSN 2675-2719 https://doi.org/10.48075/odal.v0i0.25970

etymological scope and in the appearance of other first names not present until then, with information about the history of the city.

Keywords: Onomastic; Historical Anthroponomics; Era da Hortelã

\section{Introdução}

Há diferentes maneiras de se observar a cultura, a história, a tradição e a organização de uma comunidade e uma dessas maneiras é por meio dos nomes próprios pertencentes aos moradores daquela localidade. De certa forma, os nomes próprios de pessoas carregam consigo, além de traços ideológicos, características de uma época, de uma localidade e, certamente, dos denominadores. Quando se tem, por exemplo, momentos/acontecimentos históricos, como, a exemplificar, o nascimento de um bebê da realeza, é comum observar-se, também, o grande número de nomeação de recém-natos com o mesmo nome do bebê da realeza, o que pode caracterizar a relevância da nomeação para a história.

$\mathrm{Na}$ esteira do exposto, apresenta-se estudos que versaram sobre a associação antroponímia e história em outros contextos. Zabalza-Seguin (2020a) realizou um estudo sobre a trajetória do sobrenome basco Jaso, desde sua origem no reino de Navarra, sua implantação no México na década de 1920 e suas raízes posteriores, de modo que o estudo pode evidenciar como o sobrenome afetou muitos imigrantes desta origem, em especial no relativo ao reconhecimento de sua hidalguia.

Em outro estudo ancorado nos pressupostos antroponomásticos em associação à história, a autora (ZABALZA-SEGUIN, 2020b) traz à tona uma pesquisa sobre o sistema antroponomástico durante a Idade Moderna no reino de Navarra, após a sua divisão em duas partes, as quais foram integradas à Espanha e à França. Nesse estudo, a autora constatou que o sistema onomástico tradicional que vinculava a identidade pessoal à terra natal mais do que à filiação, ao sobrenome ou ao local de vizinhança, foi mantida em meados do século 18 ao 
Onomástica Desde América Latina, n.3, v.2, janeiro - junho, 2021, p. 30 -58. ISSN 2675-2719 https://doi.org/10.48075/odal.v0i0.25970

norte de Pirineus, enquanto na Monarquia Hispânica há mais características modernas junto com um peso ainda maior do papel masculino.

Em outros estudos relativos à temática, Villegas Molina e Paz (2020a; 2020b) apresentam uma análise sobre a antroponomia mexicana em associação à história. Para tanto, no primeiro estudo, Villegas Molina e Paz (2020a) evidenciam a relevância da antroponímia para compreender a história local, uma vez que as autoras, através da antroponímia registrada nos arquivos governamentais conservados no grupo documental Mercedes del Archivo General de la Nación de México, tentam perceber as relações estabelecidas pelos diferentes atores sociais naquele período.

Além do exposto, Villegas Molina e Paz (2020b), em outro texto que versa sobre a antroponimia da região Centro-Norte do México, expõem que, a partir de estudos com base em fontes documentais sobre os sobrenomes da região, é possível constatar que os individuos da população primitiva possuiam seu próprio sistema antroponímico antes da chegada dos consquistadores, o qual sofreu grandes modificações por parte das forças imperiais europeias. Dessa forma, no estudo em questão, as pesquisadoras apresentam análises relativas aos primeiros sobrenomes hispânicos que foram utilizados para o registro indigena.

Tendo em vista os estudos apresentados e por considerar relevante a associação entre nomeação e momentos históricos, atenta-se para a influência desses no sistema antroponímico de uma comunidade, em virtude de sua relevância para a sociedade como um todo. Levando em conta que o sistema antroponímico de um local comporta características específicas desse, intenta-se, neste trabalho, apresentar a influência de um momento histórico denominado Era da Hortelã no sistema antroponímico de uma cidade, Palotina, que é localizada no interior do Paraná, Brasil. 
Onomástica Desde América Latina, n.3, v.2, janeiro - junho, 2021, p. 30 -58. ISSN 2675-2719 https://doi.org/10.48075/odal.v0i0.25970

Inicialmente, apresentam-se aspectos relativos à história do local, de modo a evidenciar o processo de colonização desse local, assim como o perfil daqueles que colonizaram e habitaram a localidade em seu início. Na sequência, expõem-se aspectos teóricos relativos à onomástica histórica, em especial no relativo à antroponímia, além de teorizar-se sobre nomes tradicionais e nomes de moda, de modo evidenciar as características que comportam cada qual. Por fim, expõe-se a metodologia empregada e analisam-se os dados, que correspondem a prenomes e sobrenomes de registrados no cartório de registro civil local naquela época.

\section{A região oeste do Paraná-PR: as terras prometidas}

A constituição da história de um local é dinâmica, ainda mais quando há espaço para a pluralidade e a diversidade. O oeste do Paraná é uma região plural em vários aspectos: na economia, na diversidade de terras e, principalmente, com relação às culturas em presença.

Constituída a partir dos anos 1930, a região oeste do Paraná reúne 50 municípios, tem uma área total de $22.840 \mathrm{~km}^{2}$, tem mais de 1.220 .000 habitantes e é localizada na fronteira com o Paraguai e com a Argentina (Figura 1).

Figura 1 - Mapa do Oeste do Paraná.

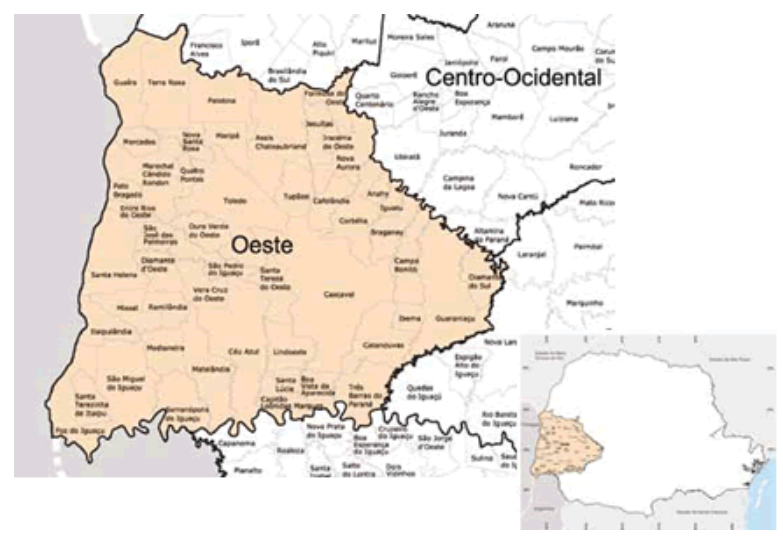


Onomástica Desde América Latina, n.3, v.2, janeiro - junho, 2021, p. 30 -58. ISSN 2675-2719 https://doi.org/10.48075/odal.v0i0.25970

Fonte: Site Cidadão Paranaense

No início de seu desbravamento, a região oeste era pouco conhecida e pouco procurada por "futuros" migrantes. Havia, contudo, forte vontade do governo da época em colonizar essa região, não só por motivos de desbravamento, mas, também, por motivos políticos e de proteção da nação. Conforme Freitag (2001):

A projeção nacionalista para os territórios do oeste do Brasil a povoar, bem como para os territórios de fronteiras internacionais, [...], nasceram, portanto, concretamente da necessidade de defesa contra os perigos visualizados pelo Estado Novo, representados pelos vazios demográficos e pela existência marcante da presença estrangeira nesses espaços. (FREITAG, 2001: 39)

Tendo em vista os perigos mencionados pela autora, o governo da época, representado principalmente pela política varguista, começou a montar estratégias para atrair migrantes para essa região, num projeto denominado Marcha para o Oeste (FREITAG, 2001: 40) que procurou atrair, por meio de propagandas vinculadas principalmente no sul do país, interessados em ter sua própria terra ou seu próprio negócio. Devido às dificuldades encontradas na agricultura do sul do país naquela época, a esperança de uma vida mais próspera convenceu os colonizadores, majoritariamente descendentes de italianos e/ou de alemães. A pregação das virtudes da região oeste do Paraná foi feita mediante panfletos, os quais são assim descritos por Pfluck (2007):

Os panfletos de propaganda destacavam, em letras maiores, que todas estas características "o Senhor encontra reunidos na Fazenda Britânia". A ênfase da propaganda fez da fazenda a Terra Prometida, terra de beleza e riqueza, o paraíso terrestre (sem morros, sem pedras e sem formigas) e um futuro promissor para a agricultura brasileira. (PFLUCK, 2007: 120) 
Onomástica Desde América Latina, n.3, v.2, janeiro - junho, 2021, p. 30 -58. ISSN 2675-2719 https://doi.org/10.48075/odal.v0i0.25970

Os panfletos distribuídos aos colonos do sul do Brasil indicavam a fertilidade do solo e a facilidade em comprar terras e financiá-las. Esse incentivo para a imigração para essa região do Paraná resultou numa formação histórica pautada por ciclos econômicos e migratórios diferentes do restante do Brasil. Enquanto na maioria do país as colonizações se pautavam pela presença de grandes fazendas, no oeste do Paraná, houve a propagação de pequenos agricultores, oriundos, em sua maioria, do Rio Grande do Sul e de Santa Catarina, que tinham como objetivo a aquisição de pequenas propriedades rurais para o próprio sustento.

A constituição do oeste do Paraná foi fruto da união de dois interesses diferentes: o das colonizadoras em obter lucro com a venda de propriedades e a dos colonos em sobreviver, conforme esclarece Deitos (2004):

Por um lado, as companhias colonizadoras têm na terra um elemento concebido como mercadoria e sua venda visa o enriquecimento dos que estão inseridos no jogo imobiliário. [...]. Os colonos chegam na região com temores, esperanças e dificuldades [...] portanto, estes têm na terra um elemento concebido como garantia de sobrevivência sua e de sua prole. (DEITOS, 2004: 24).

Com isso em vista, é legítimo supor que a constituição de diferentes movimentos migratórios para a região deu-se, sobretudo, a partir das reais necessidades dos interessados no trabalho: seja pela necessidade de trabalhar, seja pela necessidade da mão de obra. Nessa esteira, na próxima seção, apresenta-se um breve histórico do munícipio de Palotina de modo a dialogar com a história da cidade com diferentes movimentos migratórios inerentes a essa.

\section{O município de Palotina e seu processo de desenvolvimento}


Onomástica Desde América Latina, n.3, v.2, janeiro - junho, 2021, p. 30 -58. ISSN 2675-2719 https://doi.org/10.48075/odal.v0i0.25970

Localizada no oeste paranaense, a cidade de Palotina apresenta uma área equivalente a $651 \mathrm{~km}^{2}$, com população estimada em 28.000 habitantes, de acordo com o último censo do IBGE, realizado em 2010. Além disso, a população do munícipio, de acordo com o apresentado no último censo do IBGE, se concentra na região urbana (24.600 habitantes), sendo que a população rural de Palotina equivale a 4.092 habitantes.

Figura 2 - Mapa da localização de Palotina

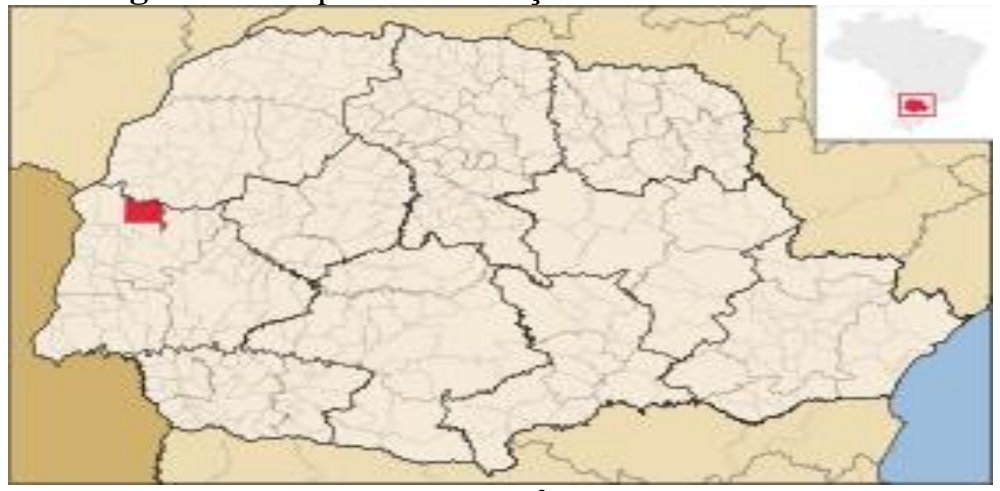

Fonte: Site Cidadão Paranaense ${ }^{2}$

Colonizada a partir da segunda metade da década de 1950, Palotina tem como atividade econômica de base a agropecuária, que contempla várias lavouras de soja e milho e várias chácaras e fazendas com criação de gado leiteiro, de suínos, de aves, de peixes e de ovinos. A empresa que fornece maior suporte aos agricultores é a cooperativa existente no município, responsável por gerar muitos empregos na cidade e por atrair muitos migrantes para a mão de obra em seu complexo avícola.

Como todas as cidades colonizadas pela "Madeireira Rio Paraná", Palotina foi planejada para ser uma cidade de descendentes de alemães e de italianos e com pouca

\footnotetext{
${ }^{2}$ Disponível em: < http://pt.wikipedia.org/wiki/Palotina\#mediaviewer/File:Parana_Municip_Palotina.svg>. Acesso em: 05 de Novembro de 2018
} 
Onomástica Desde América Latina, n.3, v.2, janeiro - junho, 2021, p. 30 -58. ISSN 2675-2719 https://doi.org/10.48075/odal.v0i0.25970

presença de pessoas de outras regiões do país. De acordo com Freitag (2001) “os Palotinos arregimentaram colonos sulistas, determinando os seus padrões comportamentais, seus códigos de honra e de fé" (FREITAG, 2001: 116). Além disso, a autora afirma que, no início da colonização da comunidade palotinense, "Palotina foi também 'pensada' a partir de um plano cultural, preparado pelo catolicismo em particular, no qual os discursos religiosos funcionavam como catalisadores das tensões e tranquilizadores dos momentos difíceis" (FREITAG, 2001: 123).

Nesse sentido, a instauração do Seminário São Vicente Palotti, logo nas primeiras décadas de colonização do município, o qual, de acordo com Reginato (1979: 130), teve sua fundação em 1970, evidencia a forte presença do catolicismo. Outro ponto a ser destacado é relativo ao nome do munícipio, visto que, de acordo com Reginato (1979), o município recebeu este nome devido à presença e à colaboração dos padres palotinos no processo de desbravamento e colonização da região.

Reginato (1979) também descreve quais eram as famílias católicas presentes na cidade, apresenta um levantamento do número de católicos em cada localidade do município e informa que os moradores de origem germânica se concentraram ao sul de Palotina, na chamada Vila Maripá, enquanto os italianos concentraram-se nas regiões centrais do município.

Outro aspecto que merece destaque quanto ao desenvolvimento da cidade de Palotina, foi a presença de uma instituição de ensino federal, a Universidade Federa do Paraná - UFPR, a partir de 1992. A vinda da UFPR para o município trouxe muitas famílias que vieram acompanhar funcionários e estudantes dessa instituição, o que contribuiu para um aumento na miscigenação da população da cidade. Além da instauração da UFPR em 1992, nos anos 
Onomástica Desde América Latina, n.3, v.2, janeiro - junho, 2021, p. 30 -58. ISSN 2675-2719 https://doi.org/10.48075/odal.v0i0.25970

2000, a principal cooperativa da cidade inaugurou um grande complexo avícola, o que ocasionou a vinda de trabalhadores de outras regiões do país e do mundo para o município.

A instalação do complexo avícola dessa cooperativa no município lembra um período no passado no qual houve forte presença de trabalhadores vindos de várias partes do país para o trabalho braçal: a chamada era da hortelã. Nota-se que, no período da Era da hortelã e também a partir da inauguração do complexo avícola, aumentou a densidade demográfica do município (Quadro 1). Ao longo do tempo, houve períodos de grande densidade demográfica e períodos de pequena densidade demográfica, oscilação que pode ser decorrente dos períodos de maior produção e maior necessidade de mão de obra nos locais.

Quadro 1 - Índice populacional de Palotina

\begin{tabular}{|l|l|}
\hline ANO & POPULAÇÃO \\
\hline 1960 & 3.469 \\
\hline 1970 & 43.005 \\
\hline 1980 & 28.248 \\
\hline 1991 & 30.705 \\
\hline 1997 & 24.783 \\
\hline 2000 & 25.771 \\
\hline 2010 & 28.683 \\
\hline
\end{tabular}

Fonte: Elaborado com dados do IBGE - Censos Demográficos

Mediante o exposto, acredita-se que os movimentos migratórios, além de contribuírem para o aumento demográfico dos munícipios, carregam consigo histórias, memórias, vivências e experiências que podem contribuir sobremaneira na constituição do sistema antroponímico de um local, visto à possível inserção de novos prenomes e sobrenomes nessas localidades. Com isso em vista, na próxima seção, apresentam-se aspectos relativos à Era da hortelã de modo que, na sequência, seja possível tecer análises, evidenciando a relação antroponímica com esse momento histórico. 
Onomástica Desde América Latina, n.3, v.2, janeiro - junho, 2021, p. 30 -58. ISSN 2675-2719

\section{A era da Hortelã e o desenvolvimento socioeconômico local}

Dentre as várias culturas agrícolas significativas para o desenvolvimento da região oeste do Paraná, destaca-se a cultura da hortelã. Ocorrido principalmente dos anos 1950 aos 1970, o cultivo da menta ocasionou o crescimento do número de migrantes nessa região. Em um primeiro momento, a vontade das colonizadoras era que o espaço do oeste do Paraná tivesse sua população totalmente constituída por sulistas, que possuíssem propriedades de terras e fizessem delas suas fontes de renda. Porém, o descobrimento de terras propícias para a hortelã deu início ao plantio desta cultura na região a qual, nas palavras de Reginato (1979),

Apresentou-se como uma das opções que acompanharam o desbravamento regional. Sendo exploração exigente, requer um solo rico em matéria orgânica e necessita de muita mão de obra. Encontrou em nossa terra condições adequadas para o seu rápido crescimento (grifos nossos). (REGINATO, 1979: 176).

A grande necessidade da mão de obra no período da era da hortelã também é revelada por Backes (2009), por meio dos relatos obtidos junto aos colonizadores de alguns municípios da região Oeste.

Era preciso limpar a roça porque para o hortelã era melhor ter uma terra bem preparada. Observei, no relato que uma das principais características assumidas pelas plantações de hortelã era a preparação do solo, contando então com a derrubada da mata e a limpeza do terreno. Supostamente, ter uma terra "bem preparada" facilitaria também lidar com o plantio de hortelã, até a colheita, quando o corte da planta era feito manualmente com gadanhas (BACKES, 2009, p. 108).

O que se percebe, então, a partir do apresentado por Reginato (1979) e por Backes (2007) é que, com o cultivo da hortelã e com os sulistas considerados latifundiários, fez-se 
Onomástica Desde América Latina, n.3, v.2, janeiro - junho, 2021, p. 30 -58. ISSN 2675-2719 https://doi.org/10.48075/odal.v0i0.25970

necessária a presença de trabalhadores no plantio e na colheita da menta. Principalmente nas décadas de 1950 e 1960, o cultivo da hortelã trouxe um forte processo de migração para essa região do Paraná, contrariando as previsões feitas pelas colonizadoras da região, conforme é destacado por Backes (2007):

Não são aqueles "selecionados" pela colonizadora no sul do país para adquirirem terras na região, mas provenientes de outras regiões como do norte e do nordeste, os quais passaram a fazer parte do espaço agrícola até então planejado do Oeste do Paraná. As lavouras, dessa feita, irromperam um processo significativo de transformações socioculturais na região. Elas utilizaram-se não somente das famílias sulistas, mas de trabalhadores vindos de outras regiões, principalmente os estigmatizados nortistas. (BACKES, 2007:3).

O intenso processo migratório ocorrido na região oeste do Paraná na "Era da hortelã" fez com que os administradores das colonizadoras da região não conseguissem mais selecionar aqueles que seriam os moradores dos municípios afetados, ocasionando uma forte onda migratória que, nas palavras do autor "permanece silenciada, pois se caracteriza como não pertencente ao projeto colonizatório” (BACKES, 2007: 8).

Assim como afetou a população de grande parte da região oeste, esse período também contribuiu para o crescimento demográfico da cidade de Palotina, o que é confirmado por Reginato (1979: 176): “nessa fase o município alcançou a sua maior densidade demográfica. O agricultor, que se dedicava a esta cultura, era na sua maioria, de origem nordestina".

O período da hortelã no oeste paranaense e suas influências já foi alvo de estudos em outros momentos: há a pesquisa de Backes (2009), que defendeu sua dissertação de mestrado em História acerca deste período nessa região, mais precisamente no município de Missal, e a de Busse (2010), cuja tese de doutorado trata sob um viés dialetológico e sociolinguístico, as influências da vinda dos migrantes nesse período na fala dos moradores dessa região. A 
Onomástica Desde América Latina, n.3, v.2, janeiro - junho, 2021, p. 30 -58. ISSN 2675-2719 https://doi.org/10.48075/odal.v0i0.25970

seção seguinte apresenta um aspecto abordado por Vescovi (2015; 2016): a influência da Era da Hortelã na antroponímia do munícipio de Palotina. Em estudos anteriores, a pesquisadora se valeu dos sobrenomes para observar quão influente foi o período no sistema antroponímico do local, mas, para este estudo, apresentam-se análises dos prenomes encontrados no local e sua possível relação com a vinda destes migrantes.

\section{Os estudos antroponímicos e a relevância histórica}

Partindo do princípio de que os nomes próprios são reveladores de culturas, ideologias e história, a investigação dos nomes próprios é direcionada por meio de uma disciplina, a Onomástica, que proporciona aos estudiosos diferentes maneiras de ver o mundo, ultrapassando os limites do meramente linguístico, atingindo o nível do social, cultural e ideológico.

O ponto de partida é o conceito de léxico, assim definido por Biderman (1998):

O léxico de uma língua natural constitui uma forma de registrar o conhecimento do universo. Ao dar nomes aos seres e objetos, o homem os classifica simultaneamente. Assim, a nomeação da realidade pode ser considerada como a etapa primeira no percurso científico do espírito humano de conhecimento do universo. (BIDERMAN, 1998: 11)

Pelas palavras da autora, percebe-se que o léxico é um inventário amplo e aberto: no léxico, estão refletidos os costumes, as tradições e as ideologias das comunidades que dele se utilizam para se expressarem e se comunicarem. O estudo do léxico de uma língua é feito a partir da Lexicologia, a ciência que "tem como objetos básicos de estudo a palavra, a categorização lexical e a estruturação do léxico" (BIDERMAN, 1998: 14), logo, entre os diferentes vieses que perpassam os estudos lexicológicos, encontram-se as investigações 
Onomástica Desde América Latina, n.3, v.2, janeiro - junho, 2021, p. 30 -58. ISSN 2675-2719 https://doi.org/10.48075/odal.v0i0.25970

sobre nomes próprios de pessoas e de lugares, objetos de interesse da Onomástica, que, de acordo com Dick (1992),

A nomeação dos lugares sempre foi atividade exercida pelo homem, desde os primeiros tempos alcançados pela memória humana. Obras antigas da história e da civilização mundiais colocam essa prática como costumeira, ainda que distinta, em certos pontos, do processo denominativo vivido modernamente. (DICK, 1992: 8)

Com base em Dick (1992), é legítimo supor uma relação estreita entre as características culturais peculiares à determinada comunidade social e a maneira pela qual seus integrantes são nomeados, relação que pode ser explicitada quando o estudo dos antropônimos é feito de maneira contextualizada historicamente.

Partindo do apresentado por Dick (1992), percebe-se que as escolhas dos nomes próprios rendem pesquisas que apontam para a cultura, para os usos e para os costumes de uma comunidade.

Face a isso, recorre-se a Al Zumor (2009), que defende que cada comunidade tem uma maneira de ilustrar suas ideologias, assim, a nomeação dos recém-natos pode ser um indicativo das ideologias de determinada comunidade:

A nomeação é um ato linguístico, intimamente ligado com os valores, tradições, esperanças, medos e eventos nas vidas das pessoas. Os nomes revelam as muitas preferências de seus donos (ou dos nomeadores) em termos de objeto da vida real, ações, conquistas e crenças (Rosenhouse, 2002). As práticas nomeadoras pessoais oferecem importantes pistas sobre a organização social e cultural das comunidades que podem ser a chave para se entender mudanças culturais mais amplas. ${ }^{3}$ (AL ZUMOR, 2009: 15).

\footnotetext{
${ }^{3}$ Naming is a specific linguistic act, intimately linked with values, traditions, hopes, fears and events in people's lives. Names reveal the many preferences of their owners (or givers) in terms of real life objects, actions, features and beliefs (Rosenhouse, 2002). Personal naming practices offer important insights into the patterns of social and cultural organization of communities and can be a key to broader cultural changes.
} 
Onomástica Desde América Latina, n.3, v.2, janeiro - junho, 2021, p. 30 -58. ISSN 2675-2719 https://doi.org/10.48075/odal.v0i0.25970

O exposto por Al Zumor (2009) é consoante ao apresentado por Dick (1992). Para ambos os autores, o nome próprio não é apenas uma forma de identificação pessoal é também um signo carregado de história e cultura que revelam o modo de ser da coletividade. Para a autora, a partir da nomeação de cada criança, é possível observar e traçar um perfil da comunidade, uma vez que

[...] os antropônimos se referem, com exclusividade, à distinção dos indivíduos entre si, no conjunto dos agrupamentos sociais, ao mesmo tempo em que permitem e possibilitam aos núcleos assim constituídos a aquisição de uma personalidade vivenciada através da nominação de seus membros. (DICK, 1992: 178)

Não obstante, outros aspectos influenciam as escolhas de um antropônimo, os quais estão relacionados a diferentes circunstâncias. Assim, ressalta-se que, para a pesquisa em desenvolvimento, levou-se em consideração as noções de nome preferencial, de moda e de tradição na escolha dos antropônimos apresentadas por Seide (2013c). As noções de moda e tradição foram elaboradas com base no comportamento estatístico dos prenomes num dado corpus. Para a pesquisadora, um prenome de moda apresenta "as seguintes características: não estar disponível no seio familiar, ser preferencial e haver descontinuidade de uso" (SEIDE, 2013c, p. 2). Um nome tradicional, por sua vez, apresenta as seguintes características: "estar disponível no seio familiar, ser preferencial e com continuidade de uso" (SEIDE, 2013c: 2).

Uma característica comum a ambas as noções é a de ser o prenome preferencial. Para Seide (2013c):

Para todos os casos, era necessário que o nome fosse preferencial. Para ser preferencial, é preciso que ele se destaque dos outros nomes em termos de frequência. Em cada elenco de nomes, eles apresentaram um comportamento estatístico diferente por haver mais ou menos dispersão de nomes com índices de riqueza vocabular distintos. Haja vista esta 
Onomástica Desde América Latina, n.3, v.2, janeiro - junho, 2021, p. 30 -58. ISSN 2675-2719 https://doi.org/10.48075/odal.v0i0.25970

disparidade, foi levada em consideração a posição relativa dos nomes em cada elenco. Outro critério utilizado foi o de não considerar nomes que não fossem preferenciais em cada elenco. Foi considerado nome não preferencial aquele que, por seu número de frequência, estive num conjunto formado pelo dobro de nomes do conjunto anterior. Exemplificando o critério: se, hipoteticamente, numa lista, a primeira posição tem um nome com frequência igual a seis, a segunda posição três nomes com frequência igual a cinco e a terceira posição sete nomes com frequência igual a dois, os nomes da terceira posição são nomes não-preferenciais. (SEIDE, 2013c: 2)

Utilizando os conceitos de nomes preferenciais, nomes tradicionais e de nomes de moda, com base nessa autora, os prenomes foram analisados observando-se a estabilidade ou instabilidade no padrão antroponímico de cada local, conforme se apresenta em seção seguinte.

Enquanto o conceito de moda se aplicaria à comunidade que apresenta maior instabilidade na escolha dos prenomes, tradição, em contrapartida, estaria aplicada àquela que possui maior estabilidade na escolha dos prenomes. Explicitados os fundamentos teóricos utilizados neste trabalho, na seção seguinte são descritos os procedimentos metodológicos empregados.

Dessa forma e de modo a investigar a relação histórica com os sobrenomes e prenomes encontrados nesta localidade, evidencia-se, em última seção, análise quantitativa de sobrenomes pertencentes à localidade e análise dos prenomes disponíveis no período pré e pós era da hortelã em comparação àqueles presentes no período da menta, de modo a evidenciar, nesta situação se há tradição ou moda no sistema antroponímico deste momento histórico.

\section{Metodologia de análise e análise dos dados}


Onomástica Desde América Latina, n.3, v.2, janeiro - junho, 2021, p. 30 -58. ISSN 2675-2719 https://doi.org/10.48075/odal.v0i0.25970

A Onomástica, tanto em seu aspecto toponímico quanto em seu aspecto antroponímico, conforme apresentado por Dick (1992), caracteriza-se pela interdisciplinaridade, haja vista suas análises dependerem de fatores que circunstanciam o espaço e o tempo. Também tem como característica a pluralidade, por contemplar visões e metodologias distintas, o que impede que haja um consenso acerca de uma metodologia única a ser seguida.

No Brasil, há estudos toponomásticos liderados pela professora Dick (1992), precursora destes estudos no país, que seguem uma metodologia estabelecida por esta pesquisadora, a qual engloba uma abordagem documental, etimológica e qualitativa dos topônimos analisados. Contudo, para as pesquisas antroponímicas não há um padrão metodológico pré-estabelecido.

Seide (2013b: 167), em um trabalho sobre a metodologia e os paradigmas das pesquisas onomásticas, apresenta uma revisão de literatura acerca das metodologias utilizadas para os estudos toponímicos e antroponímicos e cita diversas formas de estudo dos antropônimos, além da etimológica, que é a norteadora das pesquisas toponímicas. Com isso, tem-se que a maioria das pesquisas onomásticas segue o padrão estabelecido por Dick (1996 apud Ramos; Bastos, 2010) que estabelece a necessidade de haver:

1) Seleção de dados a partir de fontes primárias (no caso da antroponímia, dados coletados em cartórios de registro civil das cidades investigadas);

2) Registro dos dados em fichas lexicográficas padronizadas, com a identificação dos nomes, do pesquisador, do revisor, fontes e data da coleta;

3) A análise dos dados que inclua: 
Onomástica Desde América Latina, n.3, v.2, janeiro - junho, 2021, p. 30 -58. ISSN 2675-2719 https://doi.org/10.48075/odal.v0i0.25970

a) Quantificação dos nomes, analisando a maior ou menor frequência de classes ou itens lexicais;

b) O estudo dos nomes a partir de um enfoque puramente linguístico (etimológico e estrutural); linguístico-histórico e variacionista; histórico (relação entre a origem do nome e a histórica do local); ou geográfico.

Ainda quanto à antroponomástica e sua metodologia, ressalta-se a metodologia usada por López-Franco (2010), que adotou uma abordagem quanti-qualitativa, em uma pesquisa sobre os antropônimos de Tlalnepantla de Baz, no México, em um período de 100 anos, observando a frequência, a língua de origem e a formação morfológica dos antropônimos registrados em certidões de nascimento. Os procedimentos adotados nesse trabalho encaixam-se nos âmbitos apresentados por López-Franco (2010), sendo, então, uma pesquisa quantitativa e qualitativa de base documental.

Tanto a pesquisa quantitativa quanto a pesquisa qualitativa servem de âncora para os demais tipos de pesquisa, ou seja, norteiam as reflexões e, até mesmo, a análise de dados. Observando o apresentado por Fonseca (2002), é possível dizer que a pesquisa quantitativa está atrelada às questões de quantificação e classificação dos dados recolhidos, visto que pelas palavras do autor:

Diferentemente da pesquisa qualitativa, os resultados da pesquisa quantitativa podem ser quantificados. Como as amostras geralmente são grandes e consideradas representativas da população, os resultados são tomados como se constituíssem um retrato real de toda a população alvo da pesquisa. A pesquisa quantitativa se centra na objetividade. Influenciada pelo positivismo, considera que a realidade só pode ser compreendida com base na análise de dados brutos, recolhidos com o auxílio de instrumentos padronizados e neutros. A pesquisa quantitativa recorre à linguagem matemática para descrever as causas de um fenômeno, as relações entre variáveis, etc. (FONSECA, 2002: 2) 
Onomástica Desde América Latina, n.3, v.2, janeiro - junho, 2021, p. 30 -58. ISSN 2675-2719 https://doi.org/10.48075/odal.v0i0.25970

Concomitante à pesquisa quantitativa, tem-se a pesquisa qualitativa que, na maioria das vezes, oferece respaldo para interpretações e análises de abordagens quantitativas e, nesta pesquisa, servirá de base para as análises dos dados quantitativos encontrados, o que também é esclarecido pelo autor: "a utilização conjunta da pesquisa qualitativa e quantitativa permite recolher mais informações do que se poderia conseguir isoladamente" (FONSECA, 2002:20).

Ainda no âmbito qualitativo, observam-se as principais características desta abordagem, quais sejam: descrever, compreender e explicar. A partir das características da abordagem qualitativa. Conforme expõe Minayo (2007: 14), nessa abordagem, há o trabalho com significados, motivos, aspirações, crenças, valores e atitudes. Vindo ao encontro da conceituação da autora, a abordagem quali-quantitativa desta pesquisa pode contribuir para uma compreensão ainda maior dos valores e das atitudes das comunidades em questão.

Com relação aos procedimentos adotados para a coleta de dados, foi feita uma abordagem documental, baseada em certidões de nascimentos lavradas em cartórios de registro civil da cidade investigada. Os dados das certidões foram reproduzidos em fichas antroponomásticas como a reproduzida a seguir.

Quadro 2 - Ficha antroponomástica

\begin{tabular}{|l|l|l|}
\hline \multicolumn{2}{|l|}{ Nome próprio registrado no Cartório Civil da Comarca de Palotina } \\
\hline \multicolumn{2}{|l|}{} & \multicolumn{2}{l|}{} \\
\hline${ }^{1}$ NIVRO NO. & FOLHA do pai & \\
\hline${ }^{2}$ Naturalidade do pai & \\
\hline${ }^{3}$ Nome do pai do pai & \\
\hline${ }^{4}$ Nome da mãe do pai & \\
\hline${ }^{5}$ Nome da mãe & \\
\hline${ }^{6}$ Naturalidade da mãe & \\
\hline${ }^{6}$ Nome do pai da mãe & \\
\hline${ }^{7}$ Nome da mãe da mãe & \\
\hline${ }^{8}$ Data da Coleta & \\
\hline
\end{tabular}


Onomástica Desde América Latina, n.3, v.2, janeiro - junho, 2021, p. 30 -58. ISSN 2675-2719 https://doi.org/10.48075/odal.v0i0.25970

Coletado por

Fonte: Elaboração própria com base em Grespan (2013)

Baseando-se na metodologia proposta por Dick (1996 apud Ramos; Bastos, 2010), pode-se dizer que a coleta das informações no cartório local, preserva a identidade da comunidade estudada e contribui para uma maior precisão dos dados analisados e do resultado a ser descoberto. Para constituir o corpus de análise, optou-se por analisar os nomes dos cem primeiros registrados do munícipio de Palotina nos anos de 1957, 1970, 1971 e 1975, de modo evidenciar a presença de sobrenomes e prenomes pertencentes à comunidade naquele período. Ressalta-se, contudo, que o auge do período da menta foi nos primeiros anos da década de 1970, logo, a análise relativa aos registrados em 1957 e 1975 permitem um contraste entre os habitantes antes e após o período da menta.

\section{Os prenomes e sobrenomes na Era da Hortelã}

A “era da hortelã” influenciou não só o desenvolvimento do município de Palotina, mas, também, a diversidade cultural de seus moradores. Como se tinha conhecimento a partir das leituras feitas e de conversas com a escriturária do cartório de registro civil de que a região teve uma forte inserção da população do sudeste e do norte, principalmente nos anos 1970, foram coletados mais dados no cartório de registro civil que estivessem relacionados a este período, portanto, caracteriza-se nos gráficos abaixo a população predominante na época e nos anos investigados. Acredita-se que, por meio dos sobrenomes, é possível ter uma noção ainda mais ampla dos verdadeiros habitantes de um local e que, nesse caso, não se pode desconsiderar sua etimologia. 
Onomástica Desde América Latina, n.3, v.2, janeiro - junho, 2021, p. 30 -58. ISSN 2675-2719 https://doi.org/10.48075/odal.v0i0.25970

O primeiro ano de atuação do cartório de registro civil em Palotina foi $1957^{4}$, assim, este é o primeiro ano investigado nesse estudo. Conforme o apresentado por Reginato (1979), que menciona os sobrenomes Bortolozzo, Barbieri, De Carli e Pivetta como os de colonizadores da cidade, a cidade de Palotina comportava uma característica peculiar em sua colonização: a grande presença de famílias de ascendência ítala, o que foi previamente “planejado" pelos colonizadores da região, conforme mencionado anteriormente.

O exposto por Reginato (1979) vem ao encontro do observado nos dados referentes aos sobrenomes dos primeiros registrados em Palotina, na década de 1950, que demonstram que $50 \%$ das fichas pertencentes ao corpus tinham, pelo menos, 1 sobrenome de origem ítala.

Gráfico 1 - Etimologia dos sobrenomes dos moradores de Palotina em 1957

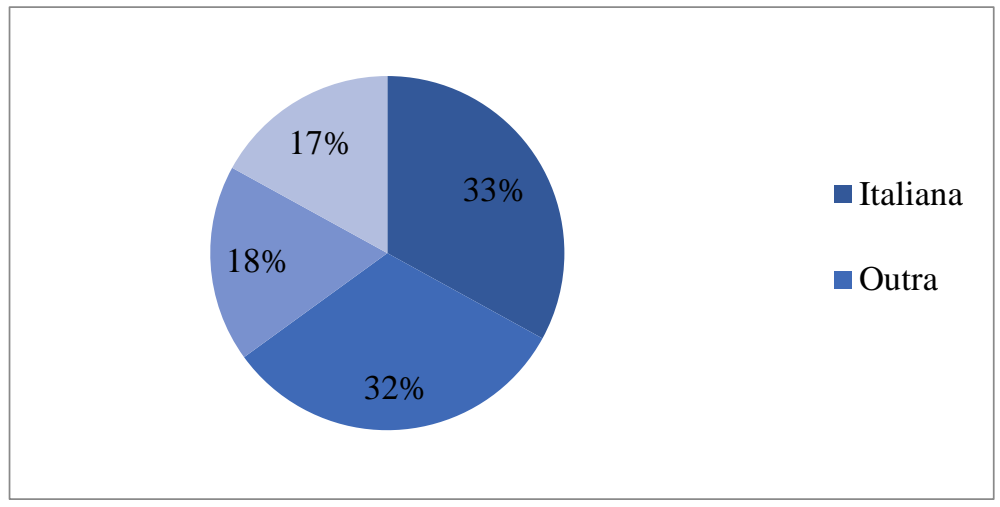

Fonte: Elaboração própria

Feitas as considerações acerca dos sobrenomes dos registrados em 1957, analisamse, então, os dados referentes ao período da hortelã, que teve seu auge uma década após o início dos registros dos nascidos em cartório de Palotina. De acordo com as análises feitas

\footnotetext{
${ }^{4}$ É importante ressaltar que neste período os registros dos nascidos na Vila Maripá, que comportava um grande número de moradores de origem alemã, eram feitos no cartório de Palotina, o que pode explicar o considerável número de fichas com sobrenomes de origem germânica.
} 
Onomástica Desde América Latina, n.3, v.2, janeiro - junho, 2021, p. 30 -58. ISSN 2675-2719 https://doi.org/10.48075/odal.v0i0.25970

com os dados coletados em 1970, apenas 10\% dos registrados continham sobrenome italiano na ficha de registro. Em contrapartida, $85 \%$ dos registrados tinham sobrenomes de outra ascendência, tais como portuguesa e luso-brasileira, ou seja, sobrenomes como "da Silva" e “dos Santos".

Gráfico 2 - Etimologia dos sobrenomes dos moradores de Palotina em 1970

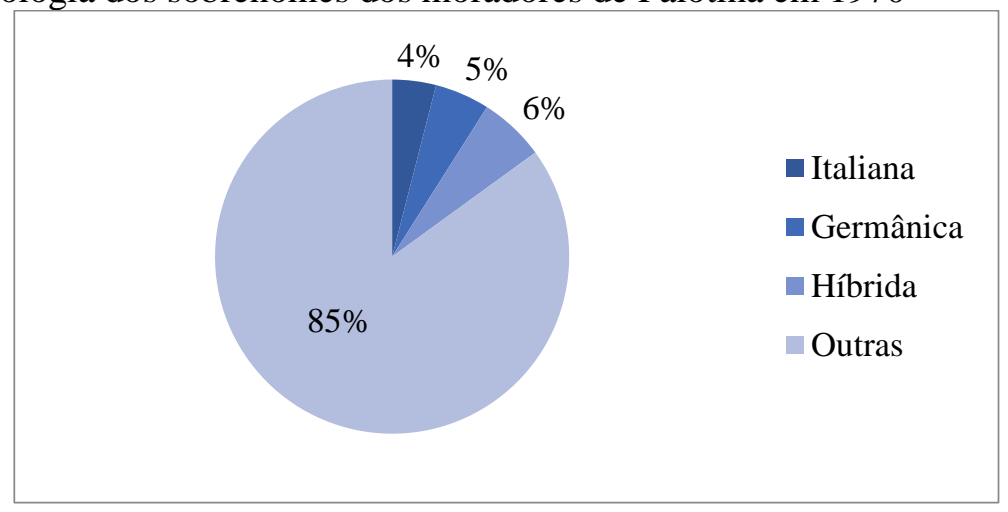

Fonte: Elaboração própria

No ano seguinte, 1971, houve uma pequena queda no número de registrados com sobrenomes de outras origens que não a ítala e a germânica, havendo, então, um aumento nos sobrenomes alemães e um considerável aumento nos sobrenomes italianos, sendo, neste período, $22 \%$ dos registrados de origem italiana ou com um sobrenome italiano na ficha antroponomástica, conforme pode ser visualizado no gráfico 3. Verifica-se, tanto neste gráfico, como no anterior, um percentual elevado de outros sobrenomes, o que pode ser atribuído à era da hortelã.

${ }^{5}$ Cumpre informar que, neste período, foi possível encontrar vários registros consecutivos com o mesmo sobrenome em decorrência de, na época, ter havido uma campanha pró-cidadania com o objetivo de promover o registro da população em cartório. 
Onomástica Desde América Latina, n.3, v.2, janeiro - junho, 2021, p. 30 -58. ISSN 2675-2719 https://doi.org/10.48075/odal.v0i0.25970

Gráfico 3 - Etimologia dos sobrenomes dos moradores de Palotina em 1971

Fonte: Elaboração própria

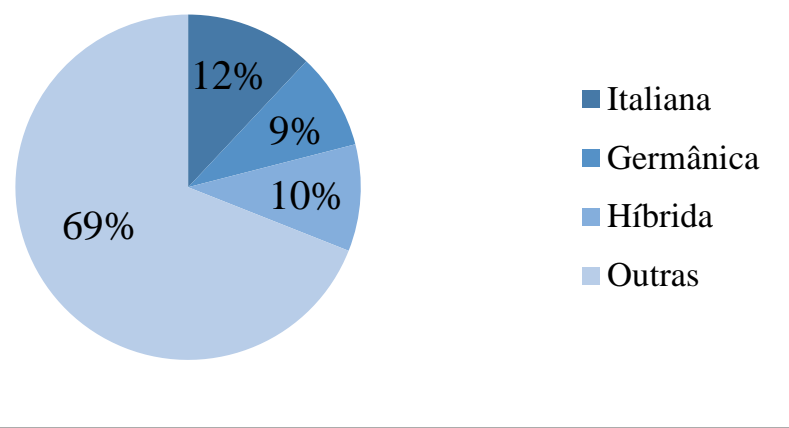

No ano de 1975, conforme se verifica no gráfico 3, as fichas antroponomásticas com sobrenomes germânicos, desapareceram e houve aumento do número de registrados com sobrenomes ítalos: de 22\%, em 1971, para 32\%, em 1975. Esta mudança na antroponímia é correlata à outra: o plantio da hortelã começava a dar espaço para o plantio de cereais, como a soja e o milho.

Os gráficos apresentados condizem às informações já mencionadas por Reginato (1979) sobre o período:

A cultura da menta acelerou o desbravamento da mata. Firmas compradoras instalaram postos de compra entre nós, e em muitos casos mantinham a produção sob contrato de financiamento monetário e de produtos fitossanitários com os agricultores [...] Mas colocava o agricultor numa dependência total do comprador [...] O óleo da menta provou o seu auge no início dos anos 70. Mas logo decresceu, para desaparecer em cinco anos. Este ciclo acompanhou a suinocultura e foi paralelo à corrida da mecanização agrícola, para logo extinguir-se. (REGINATO, 1979, pp. 176177)

É possível verificar, no gráfico 4, que, dentre as famílias com outras ascendências, há um ligeiro crescimento de 1957 a 1970 e uma pequena queda de 1971 a 1975 . Por outro lado, observa-se, também, que os sobrenomes italianos predominantes em 1957 diminuíram ao longo do tempo e que os sobrenomes germânicos, consideravelmente presentes nesta época, 
Onomástica Desde América Latina, n.3, v.2, janeiro - junho, 2021, p. 30 -58. ISSN 2675-2719 https://doi.org/10.48075/odal.v0i0.25970

sumiram com o passar dos anos, o que está diretamente atrelado ao fato dos registros de Maripá serem feitos, até 1966 no município de Palotina e, depois desta data, serem feitos na própria vila, que, de acordo com informações históricas, concentra um maior número de alemães.

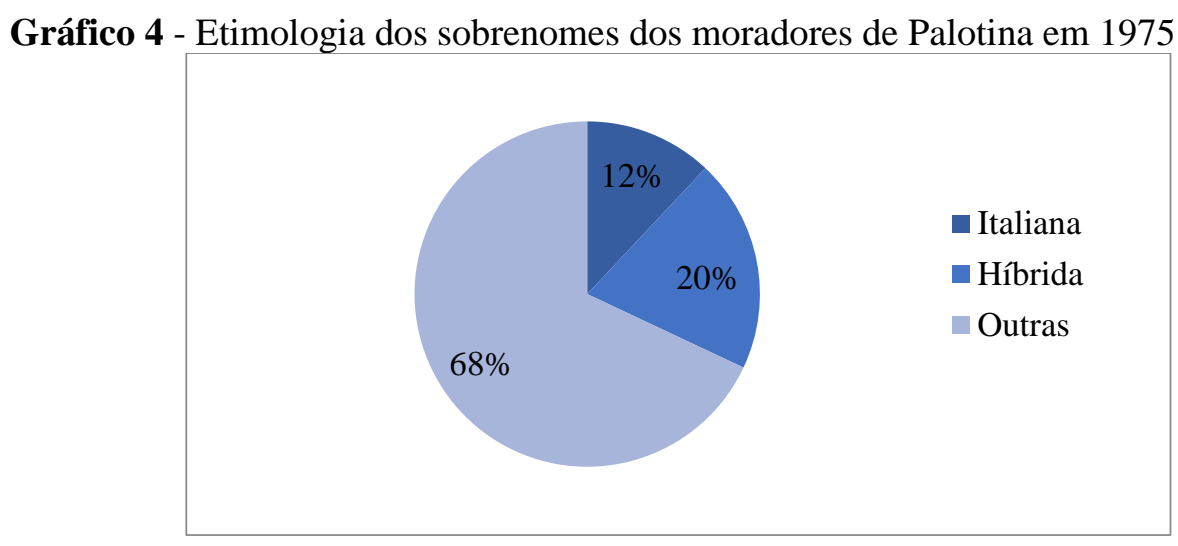

Fonte: Elaboração própria

A partir dessas informações, traça-se, no gráfico 5, um delineamento das análises feitas até então a fim de comparar as diferenças encontradas em cada período no munícipio de Palotina.

Gráfico 5 - Etimologia dos sobrenomes dos moradores Palotina no período de 1957 a 1975 
Onomástica Desde América Latina, n.3, v.2, janeiro - junho, 2021, p. 30 -58. ISSN 2675-2719 https://doi.org/10.48075/odal.v0i0.25970

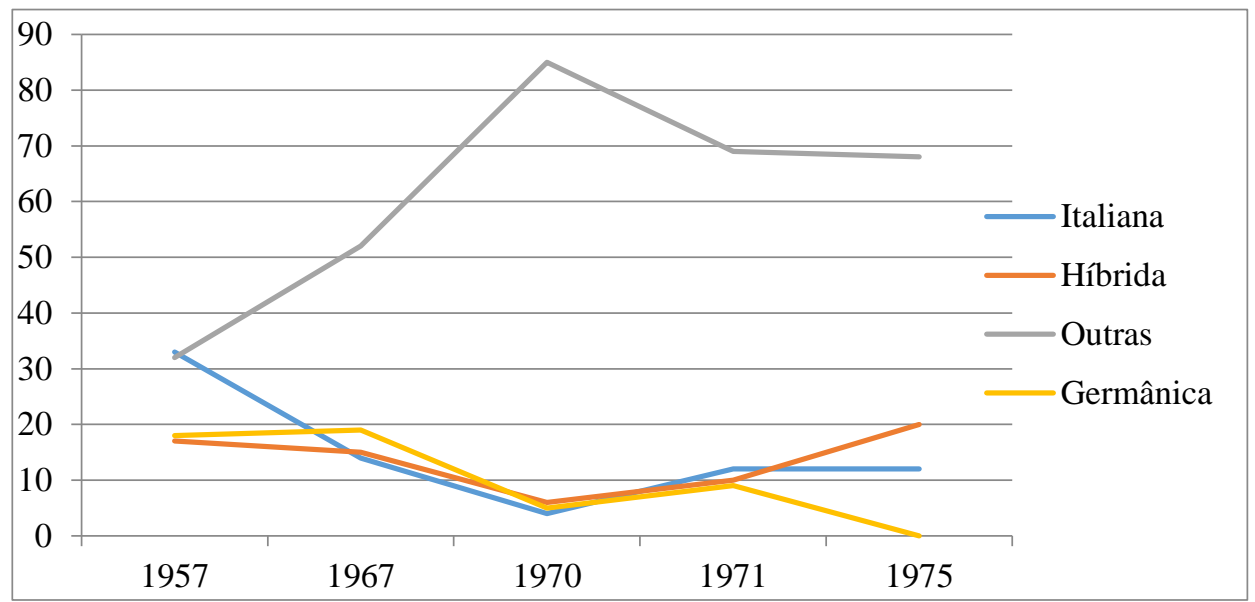

Fonte: Elaboração própria

A partir da observação do gráfico acima, percebe-se que a Era da hortelã acarretou algumas mudanças na antroponímia da cidade de Palotina, principalmente no que diz respeito aos sobrenomes dos registrados, os quais indiciam as famílias que habitavam a cidade. Ora cumpre retomar os dados fornecidos pelo censo demográfico, obtidos através do IBGE. Enquanto, em 1960, a cidade tinha menos de 3.500 habitantes, em 1970, a cidade chegou a alcançar o marco de mais de 43.000 habitantes, a grande maioria para trabalhar no plantio da hortelã, como já exposto. Era de se esperar, portanto, que houvesse, nessa época, um maior crescimento de famílias oriundas das regiões norte e nordeste, tendo em vista que, conforme já apresentado por Reginato (1979), era dessas regiões que vinham as famílias para trabalhar na era da hortelã. Além disso, outro fato interessante de se ressaltar é que, certamente, em 1957, haveria mais italianos do que portugueses/brasileiros na comunidade, tendo em vista que este foi o período de colonização do município.

No relativo aos prenomes, foram elencados para análise os prenomes relativos à década de 1950, ao período da menta, incluindo os anos de 1970 e 1971, e, também, ao ano de 1975, de modo a se fazer uma análise comparativa, os quais foram expostos nos quadros 
Onomástica Desde América Latina, n.3, v.2, janeiro - junho, 2021, p. 30 -58. ISSN 2675-2719 https://doi.org/10.48075/odal.v0i0.25970

abaixo, o primeiro relativo aos prenomes masculinos e o segundo relativo aos prenomes femininos, de modo a facilitar análise e a exposição dos dados.

De modo a justificar a classificação abaixo, informa-se que se considerou como prenomes tradicionais aqueles que apareceram no corpus mais de uma vez e em diferentes anos e como prenomes da moda aqueles que apareceram apenas uma vez no corpus em questão e são referentes a períodos específicos.

Quadro 3: Elenco dos prenomes masculinos

\begin{tabular}{cll} 
Ano & \multicolumn{1}{c}{ Prenomes tradicionais } & \multicolumn{1}{c}{ Prenomes novos/da moda } \\
1957 & $\begin{array}{l}\text { Antônio (3), Eliseu (2), Jaime (2), } \\
\text { José (2), Paulo (2), Pedro (2) }\end{array}$ & Erudé, Niomar, Julinê. \\
1970 & $\begin{array}{l}\text { Antônio (5), João (5), José (4), Edson } \\
\text { (2), Francisco (2), }\end{array}$ & Enori, Ori. \\
1971 & José (5), João (4) & Elpidio, Elvécio, Jovernal, \\
1975 & $\begin{array}{l}\text { José (3), Carlos (2), Elias (2), Luiz } \\
\text { (2), Roque (2) }\end{array}$ & Cresvesvalto, Krauer, Silso.
\end{tabular}

Fonte: Elaboração própria

Pelo observado na tabela acima, é possível constatar que prenomes como Antônio, João e José são prenomes tradicionais da região, independente do momento histórico e dos habitantes daquele lugar, o que configura um padrão na norma antroponímica local. Ademais, deve-se ressaltar que a repetição de prenomes em determinada década também pode estar associado aos fatos históricos daquele momento. Quanto aos prenomes "novos" ou de “moda”, observa-se que há o emprego de prenomes não encontrados em outras décadas, os quais, em sua maioria, são oriundos de famílias vindas para o período da menta, o que pode ser confirmado ao observar a origem da família como sendo de Minas Gerais, Pernambuco e São Paulo. Acredita-se, também, que a pouca repetição de prenomes neste local, ou, a grande 
Onomástica Desde América Latina, n.3, v.2, janeiro - junho, 2021, p. 30 -58. ISSN 2675-2719 https://doi.org/10.48075/odal.v0i0.25970

variedade no acervo de prenomes disponível, pode estar relacionada ao grande número de prenomes disponíveis para a nomeação, o que caracteriza, de fato, a escolha pessoal do designador. Considerando, então, o emprego de alguns prenomes masculinos não disponíveis no sistema antroponímico anteriormente, acredita-se que o período da menta contribuiu para a inserção destes no sistema antroponímico masculino local.

No relativo aos prenomes femininos empregados no local, é perceptível, de acordo com o quadro abaixo, uma menor repetição de prenomes, ou seja, uma menor quantidade de prenomes tradicionais. No entanto, no tocante a prenomes "novos" ou "de moda", é constatável o considerável aumento destes no período da menta.

Quadro 4: Elenco dos prenomes femininos

\begin{tabular}{|c|c|c|}
\hline Ano & Prenomes tradicionais & Prenomes novos/da moda \\
\hline 1957 & Maria (4), Liane (2) & Alcira, Andrelina, Frozina, Jorite \\
\hline 1970 & $\begin{array}{l}\text { Maria (10), Cleusa (4), Neusa (3), } \\
\text { Geni (2) }\end{array}$ & Aurentina. Hermelinda, Rutinéia, \\
\hline 1971 & $\begin{array}{l}\text { Maria (7), Marlene (2), Marli (2), } \\
\text { Roseli (2) }\end{array}$ & $\begin{array}{l}\text { Augelida, Carmira, Geuelzira, } \\
\text { Ingueltraud, Inguelori, Juventina, } \\
\text { Narminda. }\end{array}$ \\
\hline 1975 & $\begin{array}{l}\text { Maria (8), Adriana (3), Rosangela } \\
\text { (3), Sandra (2) }\end{array}$ & Alvina, Cosma, Marionice. \\
\hline
\end{tabular}

Fonte: Elaboração própria

Com a exposição da tabela relativa aos prenomes femininos, é possível constatar que, em comparação aos prenomes masculino, os prenomes femininos são mais inovadores, ou seja, no período da menta, o surgimento de prenomes femininos não disponíveis até então em nosso corpus é maior, o que traz à tona um importante dado: há, neste momento, maior inovação quanto aos prenomes femininos a os prenomes masculinos. 
Onomástica Desde América Latina, n.3, v.2, janeiro - junho, 2021, p. 30 -58. ISSN 2675-2719 https://doi.org/10.48075/odal.v0i0.25970

No entanto, deve-se ressaltar que o surgimento destes prenomes corroboram novamente para atenuar uma questão já informada no relativo aos sobrenomes: a vinda destes migrantes colaborou não apenas para a mão de obra, mas também para a incorporação de novos prenomes e novos sobrenomes ao sistema antroponímico do local, o que comprova, mais uma vez, a relevância da antroponímia de um local para a compreensão de fatos históricos e das pessoas vinculadas a estes.

\section{Considerações finais}

A história de uma comunidade pode ser comprovada por meio dos dados antroponímicos. É o que mostram os resultados atingidos por esta pesquisa, que faz parte de uma maior. No munícipio de Palotina foi possível correlacionar as mudanças antroponímicas com as informações sobre a história do município. Houve presença significativa de sobrenomes de outras etnias que não a ítala e a teuta no período da hortelã, considerado um dos períodos de maior riqueza e de maior densidade demográfica do local, o que comprova a ideia de que os movimentos migratórios não é apenas constituído de pessoas, mas de culturas, histórias e memórias. Mediante o exposto, é importante destacar que o contraste entre os nomes tradicionais e os nomes de moda só é passível de análise numa perspectiva relativística, uma vez os nomes tradicionais locais também são oriundos de movimentos migratórios anteriores, o que, de certa forma, contribui para a sua hipótese e constatação de que momentos históricos impactam a antroponímia local, ou seja, movimentos ao logo do tempo são passíveis de serem compreendidas no/pelo espaço.

Ainda com relação ao período da hortelã, a vinda de novos moradores para o local implicou na introdução de novos prenomes no sistema antroponímico local, indicando haver 
Onomástica Desde América Latina, n.3, v.2, janeiro - junho, 2021, p. 30 -58. ISSN 2675-2719 https://doi.org/10.48075/odal.v0i0.25970

uma estreita relação entre a migração e a evolução da antroponímia palotinense. Contudo, ressalta-se que esses são os primeiros estudos sobre a antroponímia da região oeste e intentase, a partir destas constatações, observar outros aspectos que relacionam, diretamente, nomes e história, uma associação passível de comprovações das reais condições de cada local.

Recebido em 03/09/2020 Aceito em 23/09/2020 Publicado em em 17/12/2021

\section{Referências}

Al-Zumor, Abdul Wahed Qasem Ghaleb (2009) "A Socio-Cultural and Linguistic Analysis of Yemeni Arabic Personal Names" GEMA Online: Journal of Language Studies. Bangi, Malásia, v. 9, $\quad$ n. 2, pp. 15-27, 2009. Disponível em: < http://www.ukm.my/ppbl/Gema/pp\%2015_27. pdf>. Acesso em: 29 out. 2018.

Backes, Gilson (2007) "Narrativas e memórias: os trabalhadores do ciclo hortelaneiro (Oeste do Paraná, 1960-1970)" in Anais do IV Encontro Regional Sul de História Oral: Culturas, Identidades e Memórias, Florianópolis, 2007, pp. 01-08 (Anais Eletrônicos). Disponível em: - www.cfh.ufsc.br/abho4sul/pdf/Gilson\%20Backes.pdf Acesso em: 25 jun. 2014.

Biderman, Maria Tereza Camargo. O Léxico. In: Oliveira, Ana Maria Pinto Pires; Isquerdo, Aparecida Negri. (Orgs.). As ciências do léxico: lexicologia, lexicografia, terminologia. Campo Grande: Editora UFMS, 1998

Busse, Sanimar (2010) Um estudo geossociolinguístico da fala do Oeste do Paraná. Londrina. Tese (Doutorado em Estudos da Linguagem) - Programa de PósGraduação Stricto Sensu em Estudos da Linguagem. Universidade Estadual de Londrina, Londrina - PR.

Deitos, Nilceu Jacob (2004) Presença da Igreja Católica no Oeste do Paraná: a construção do imaginário católico (1930-1990). Porto Alegre, 2004. Tese (Doutorado em História) - Programa de Pós-Graduação Stricto Sensu em História. Universidade Federal do Rio Grande do Sul, Porto Alegre - RS.

Dick, Maria Vicentina de Paula do Amaral (1992) Toponímia e Antroponímia no Brasil. Coletânea de Estudos. 2a. Ed. São Paulo: FFLCH. 
Onomástica Desde América Latina, n.3, v.2, janeiro - junho, 2021, p. 30 -58. ISSN 2675-2719

https://doi.org/10.48075/odal.v0i0.25970

Freitag, Liliane da Costa. Fronteiras perigosas: migração e brasilidade no extremo-oeste paranaense (1937 - 1954). Cascavel: EDUNIOESTE, 2001.

Gregory, Valdir. Os eurobrasileiros e o espaço colonial : migrações no Oeste do Paraná (1940-1970). 2. reimpr. Cascavel: Edunioeste, 2008. Disponível em: <http://www.unioeste.br/editora/pdf/livro_eurobrasileiros_espaco_colonial_valdir_g regory.pdf >. Acesso em: 18 jun. 2013.

Pflufk, Lia Dorotéia. Os aspectos naturais na propaganda da colonização de Marechal Cândido Rondon. In: Vanderline, Tarcísio; Gregory, Valdir; Deitos, Nilceu Jacob (Orgs. ). Migrações e a construção do Oeste do Paraná: século XXI em perspectiva. Cascavel: Coluna do Saber, 2007, p.119-142.

Reginato, Pedro (1979) História de Palotina. Santa Maria: Palloti, 1979.

Seide, Márcia Sipavicius (2012) "Importância relativa da etimologia para análise dos antropônimos" Anais do X Encontro do Celsul - Círculo de Estudos Linguísticos do Sul. Cascavel - PR: Unioeste, 2012. Disponível em: <http://www.celsul.org.br/Encontros/10/ artigos/AnaAmaliaSouza. htm>. Acesso em: 18 Nov. 2018.

Seide, Márcia Sipavicius (2013a) "Motivações contemporâneas para a escolha do antropônimo" Entreletras. Araguaína, TO, v. 4, n. 2, pp. 90-101, ago-dez/2013a.

Seide, Márcia Sipavicius (2013b) “Toponomástica e Antroponomástica: paradigmas e métodos" Revista Confluência. Rio de Janeiro, n. 44/45, pp. 165-184, 2013b. Disponível em: <http://llp.bibliopolis.info/confluencia/pdf/1192.pdf>.

Seide, Márcia Sipavicius (2013c) "Moda e tradição na antroponímia de Marechal Cândido Rondon” IX ENGTLEX. Resumos Expandidos. Caxias do Sul - RS: UCS, 2013c, pp. 1-3. Disponível em: <http://scholar.googleusercontent.com/ scholar?q=cache:v8eK7F3w0_MJ:scholar.google.com/+moda+e+tradi\%C3\%A7\%C $3 \%$ A3o+na+antropon\%C3\%ADmia+de+marechal\&hl=pt-BR\&as_sdt=0,5>. Acesso em: 3 nov. 2018. (Resumo expandido)

Vescovi, Jéssica Paula (2015) Prenomes e sobrenomes em Palotina-PR e Maripá-PR: um estudo comparativo. 2015. 112f. Dissertação (Mestrado em Letras) - Universidade Estadual do Oeste do Paraná - UNIOESTE, Cascavel.

Vescovi, Jéssica Paula (2016) "O impacto da Era da Hortelã no sistema antroponímico de Palotina e Maripá (PR)” Revista ENTRELETRAS, Araguaína/TO, v. 7, n. 2, jul./dez. $2016 . \quad$ Disponível em: https://sistemas.uft.edu.br/periodicos/index.php/entreletras/article/view/2946/9486 Acesso em 25 de jan. 2018. 
Onomástica Desde América Latina, n.3, v.2, janeiro - junho, 2021, p. 30 -58. ISSN 2675-2719 https://doi.org/10.48075/odal.v0i0.25970

Villegas Molina, María Elena; Brambila Paz, Rosa (2020a) Antroponimia registrada en las Mercedes de Jilotepec, siglo XVI. Onomástica Desde América Latina, n.1, v.1, (janeiro - junho): 122 -144. Disponível em: http://erevista.unioeste.br/index.php/onomastica/article/view/24162. Acesso em: 17 out. 2020.

Villegas Molina, María Elena; Brambila Paz, Rosa (2020b) Apellidos hispánicos en Centro-Norte de Nueva España, siglo XVI. Onomástica Desde América Latina, n.2, v.1, (julho - dezembro): 103 - 121. Disponível em: http://erevista.unioeste.br/index.php/onomastica/article/view/25489. Acesso em: 17 out. 2020.

Zabalza Seguín, Ana (2020a) Del solar bajonavarro a la Nueva Espanã: el viaje de Juan de Jaso (1523). Onomástica Desde América Latina, n. 1, v. 1. Disponível em: http://erevista.unioeste.br/index.php/onomastica/article/view/24157. Acesso em: 17 out. 2020.

Zabalza Seguín, Ana (2020b) El papel del estado en la formación de los apellidos: la Navarra francesa y la Navarra española. Onomástica Desde América Latina, n. 2, v. 1, (julho - dezembro): 17- 44. Disponível em: http://erevista.unioeste.br/index.php/onomastica/article/view/25491. Acesso em: 17 out. 2020. 